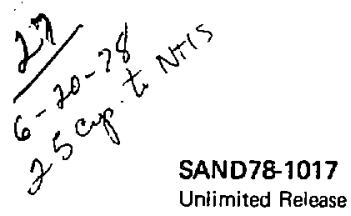

\title{
The Design of Integrated Safeguards Systems for Nuclear Facilities
}

J. M. deMontmollin, R. B. Walton

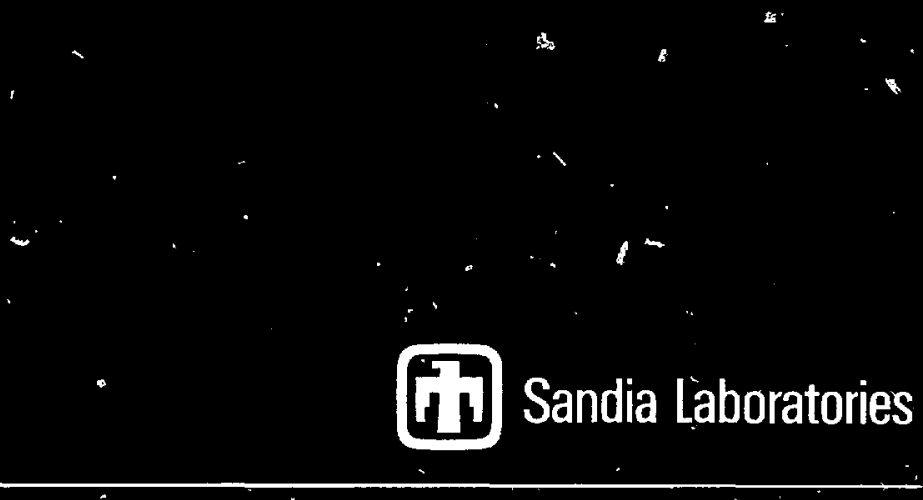


Issued by Sandia Laboratories, operated for the United States Department of Energy by Sandia Corooration.

\section{NOTICE}

This report was prepared as an account of work sponsored by the United States Government. Neither the United States nor the United States Department of Energy, nor any of their employees, nor any of their contractors, subcontractors, or their employees, makes any warranty, express or implied, or assumes any legal liability or responsibility for the accuracy, completeness or usefulness of any information, apparatus, product or process disclosed, or represents that its use would not infringe privately owned rights.

Printed in the United States of America

Available from

National Technical Information Service

U. S. Department of Commerce

5285 Port Roval Road

Springfield, VA 22161

Price: Printed Copy \$4.00; Microfiche $\$ 3.00$ 


\section{THE DESIGN OF INTEGRATED \\ T.QFEGLARDS SYSTE:IS}

\section{FOR NUCI.EAR FACILITIES*}

J. M. de Montmollin

Staff Member

Facilities Protection Department

Sandia Laboratories

Albuquerque, New Mexico

R. B. Walton

Alternate Group Leader

Nuclear Analysis Research

Los Alamos Scientific Laboratory

Los Alamos, New Mexico

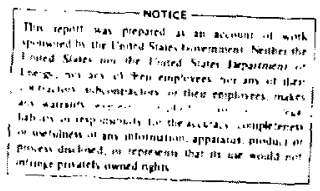

\section{Abstract}

Safeguards systems that are capable of countering postulated threats to nuclear facilities must be closely integrated with plant layout and processes if they are to be effective and if potentially-severe impacts on plant operations are to be averted. This paper descrihes a facilities safeguards systeñ suitable for production plant, in which the traditional elements of physical protection and periodic material-balance sccounting are extended and augmented to provide close control or material flows. Discrete material items are subjected to direct, overriding physical control where appropriate. Materials in closely-coupled process streams are protected by on-line MDA. and weight measurements, with rapid computation of material balances to provide inmediate indication of large-scale diversion. The system provides an information and actions at the safeguarcis/ operations interface.

\section{The Problem}

The postulated threat to nuclear materials has grown to the point that extensions of conventional safeguards techniques have become increasingly burdensome. New threats and avenues for diversion are continually being postulated, and incremental extensions of conventional measures intrude further on plant operations. What is needed is an integrated strategy for in-depth protection of materials in facilities that provides better effectiveness without unreasonable operational impact.

$\overline{\mathrm{ETE}}+\overline{\mathrm{S} \text { work }}$ was supported by the U.S. Energy Research \& Development Administration. 
Traditionally, facility safeguards systems have evolved in two separate areas that heretofore have had little interaction: physical protection and materials control and accounting. Physical protection has followed the conventional industrial-security strategy of exclusion; that is, by protecting a secure operating area against unauthorized entry. The accountability of materials within a plant and the detection of losses or unauthorized removals have reliec heavily on material-balance accounting follow ing periodic shutdown, cleanout, and physical inventory. During periods of routine production, the control of materials in facilities is vested largely in administrative and process controls, augmented by secure storage for discrete items. Because of the limited capacity for prompt detection of urauthorized removals or losses, especially those involving small quantities of material, there has been increasing emphasis on the development of automated systems for real-time measurement and control, such as the DYMAC (Dynamic Materials Control) system.

The postulated threats of overt attack have escalated to the point that they are difficult to counter by conventional industrial-security methods. The authority of private security guards is seldom openly challenged in most non-iuclear installations, and the legull and other constraints under which private guards must operate do not seriously limit their effectiveness. The forces postulated to threaten nuclear installations have grown far boyond the levels faced by most industrial facilities. In an escalation between hypothetical opponents and real-world security forces, the defenders are invariably outclassed. If the facilities are indeod to be protected against such threats, new approaches must be found to replace conventional security-force operations. Strategies for protection must be developed that enhance the inherent advantages of the defenders, so that the outcome is less sensitive to relative armed strengths.

\section{Limitations of Conventional Approaches}

A comprehensive safeguards strategy includes three functions: (1) the exclusion of all unauthorized persons from the facility, with further exclusion from sensitive areas within the plant; (2) control of all activities involving materials to preclude any that are not specifically authorized; and (3) confirmation that all matcrials are present at their proper locations. The system for implementing that strategy must operate without unnecessary disruption of plant operations, compromise of safety requirements, or infringements on employee working conaitions. The first function.-exclusion and entry control--is the traditional function of the security force. It is in effect a personnel control function; it involves the prevention of forcible entry, the identification of those authorized to enter, and enforcement of security regulations governing those who are admitted. The third function--quantitative confirmation of material possession and flows-is accomplished by the materials accounting system. 
The second function, controlling activities involving materials within the facility is not covered directly by either of the traditional safequards elements. Earlier, it was not considered a problem-ordinary production process control and supervision were deemed sufficient. As the threat has escalated to include employee collusion and the risk of forcible takeover, the approach has bzen to try to cover that area by extensions of the ot ier two furctions--keep employees under surveillance by guards, add barriers, and close material balances more frequently to detect losses.

Surveillance is limited in effectiveness because of the problem faced by guards having to make judgments on the basis c. $\mathrm{f}$ what they can see. That is aifficult at best; furthermore, al: unauthorized activities are not necessarily visible. Barriers must allow routine passage of workers and materials. Materials control and accounting suffors from resolution and timeliness limitations; depending on the quantity involved, a discrepancy may not be detected soon enough to prevent irretrievable loss. The principal objective for materials measurement technological development has been to improve both accuracy and timeljness, and a. thesc cilatalel -slics improve, successively tighter saleguards can be applied to materials in process with minimal impact on productivity.

\section{Safeguarding Production Operations}

The problem of control of activities within the plant at the personnel/materials interfaces is being approached somewhat differently for materials in process and for discrete items in storage and handling. For the former, continued improvements in measurement techniques and accounting systems are expected to progressively restrict the vulnerability to loss or diversion. Frequent computation of material balances on adjacent unit processes and correlations of material flows at various parts of the process stream will improve the capability for rapid detection of losses of relatively smaller quantities. With new systems for personnel entry control, personnel access to critical process areas and work stations car be applied more selectively. As safeguards control measures are tightened around process lines, there is a potentia] for serjous impacts on production operations. process-line safeguards must therefore be very carefully integrated with operations if the safeguards are to gain acceptance, and if the indirect costs are to remain under control.

The handing and storage of discrete items, especially at the transportation interfaces for feed and product, are less closely coupled to matarial flows. At the same time, vulnerabilities to certain kinds of threats are more serious. Packaged materials are more easily moved. When not secured in vaults, packaged materials are relatively more accessible. Judging by the experience with theft of general cargo in the transportation industry, most losses occur in terminal areas, where materials are directly handled by lower-level poople, and where administrative 
controls are easily subverted. Overt, forcible attacks intent on theft would likely be directed at seizure of those parts of the plant where discrete items are handled, since those items are more easily carried off-site.

Item handing operations that are not closely coupled to process flows can be prescribed as sequences that are amenable to remote monitor and overriding control. Direct control of any uperation is a process of monitoring, comparison with a standard of acceptance, and corrective control action when deviations are detected. For safeguards control of itern handling operations, the threats of internal collusion and of forcible takeover iequire that the monjtor, decision, and control actions be beyond the reach of those with direct access to the material. An iterhandling sequence such as unloading and storing an incoming shipment of feed material could be designed so as to require the use of specialized containers and handing equipment. If signals indicated a departure from the normal sequence, or if activities did not correlate with authorizing information conveyed separately to the safeguards unit, control action could be imposed remotely to imnobilize the material or to generate other appropriate responses. The control sequence could be proqrammed for automatic action when safeguards criteria were violated, unless the consequences of the control action on plant processes were so complex as to require operator intervention. There are many operations, which we have generally termed as item handling operations, where programmed control actions and preplanned responses could be initiated without human intervention. The strategy for safeguarding iiem handing operations is to monitor the jperation itself--personnel identification and equipment status as bell as material item identification--and impose direct control action if departures from authorized sequences are detected. In the event of forcible occupation of an item handling area, the remote control actions could be imposed to imperie movement of the material offsite. Safeguards control will override normal operations only when a threat is clearly indicated, and where the operational impact extends beyond the area directly involved, human intervention will be provided to avert adverse transient effects on processes.

\section{Structure of the Integrated System}

The general block diagram for the facility safeguards system is shown in Figure 1. At the heart of the plant is the frocess itself which has been divided into unit processes and item control areas for control and accounting purposes. Each unit process has an associated controller, which may be a man/machine subsystem, and which determines the control actions necessary to drive its unit process to the desired setpoint. The setpoint, or operating condition, of each unit process is specified by the Process Control Coordination unit on the basis of operational authorizations, optimaj. process operation considerations, and safety. 


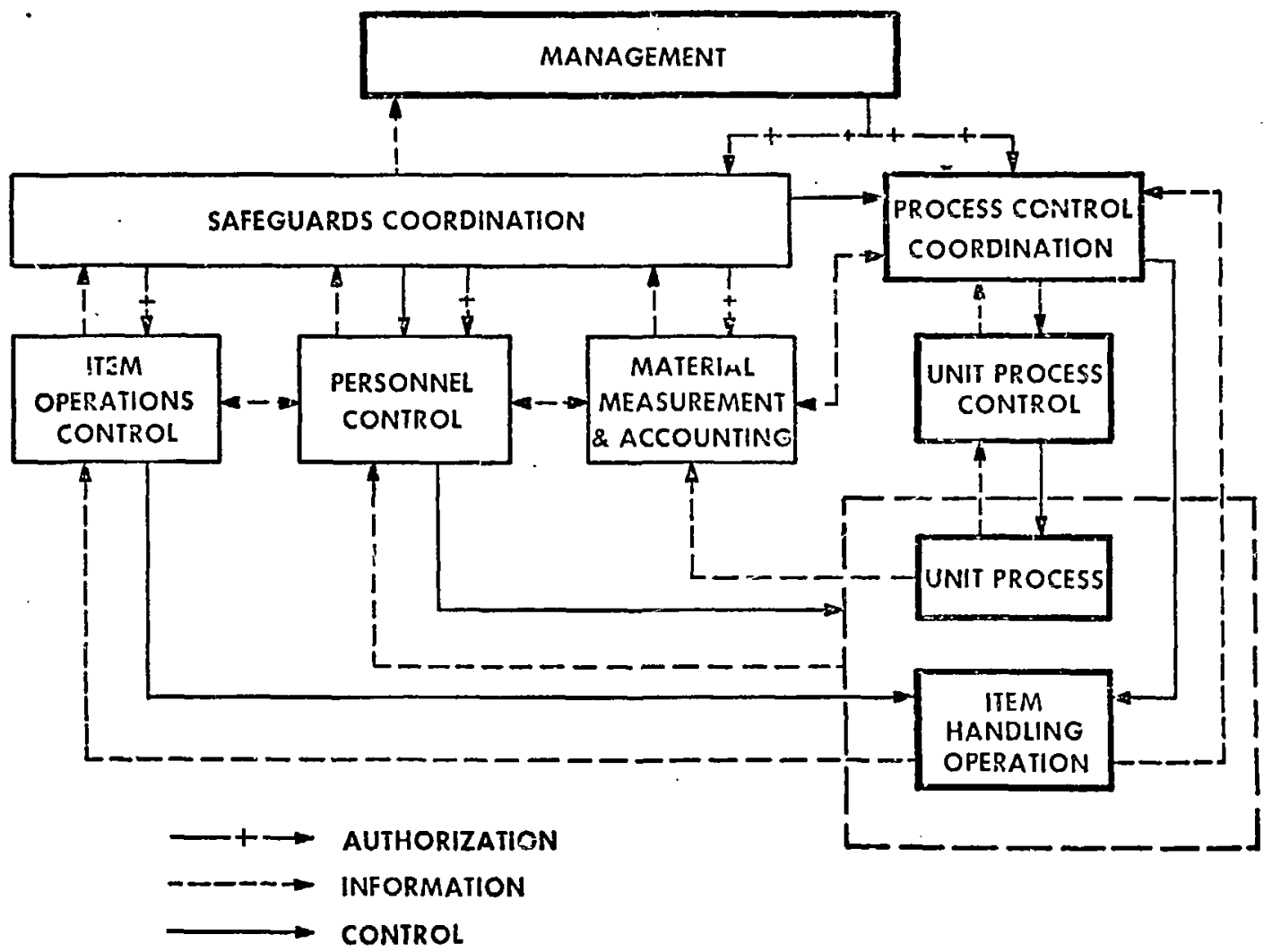

\footnotetext{
Figure 1 - General Structure of Safeguards Syster.
} 
Each item control area is under the direct supervision of the Item Operation Control function. This arrangement provides more effective protection through remote, overriding control of discrete material items in handing and storage. The concept is applied only to those portions of the plant outside the closelycoupled process line where material flow is not critical to smooth process operations.

The Process Control Coordination unit (PCC) may be a computer, a human operator, or a committee of decision-makers; most likely it will be a combination of these. Its functions include not only process control, but also process data summarization and reporting and safety interactions. It is capable of using the data from the Materials Measurement and Accounting system in an adaptive fashion to help improve the process operations. It also defines operational procedures to be followed when the Safeguarä; Coordination unit (SC) modifies the operational authorization, as would be the case for overt diversion detection, for example. Normally, all actions which might affect process operations are executed through the process Control Coordination unit. An exception is safety-related responses which sometimes require direct action in emergencies.

The remainder of the block diagram is primarily the safegua:d: system. The Safeguards Coordination unit modifies the work authorizations from management according to its assessment of the safeguards status of the plant. For example, if the safeguards status is satisfactury, the management work authorization is unmodified. However, if covert diversion has been detected or if an attack is imminent, SC directs the PCC to control the process to a relatively secure state, to further restrict the accessibility of materials. The SC unit also transmits continuously the safeguards status to the Materials Measurement and Accounting System (MMAS) for information only, and to the Personnel control element so that the security forces status and deployment is appropriate. As in the case of the PCC, the safeguards control unit will probably be some manmachine combination to combine reliability and capacity with the adaptability afforded by human judgment.

\section{Personnel Control Element}

The Personnel Control Element includes the conventional security functions, extended in depth and integrated closely with the other system elements. The security function is, in a broad sense, synonymous with personnel control. It maintains isolation of materials by prevention of all unnecessary access. By use of systems of barriers and controlled entry points, personnel controls act to:

Prevent all passage across barriers except at designated portals. The problem of authorization is thereby localized by restraining all passage elsewhere. 
- Prevent entry at designated portals by those not specifically authorized to enter. Admission is bosed on identification and authorization specifying the conditions governing permission to enter. Authoriaation may be subject to two kinds of conditions:

-- Fixed conditions, which abply to a particular individual whenever antry is sought. Fixed conditions may include provisions for such things as the operating state of the facility and time-of-day restrictions.

-- Special conditions, which allow an individual to enter on a one-time basis to participate in a particular operation. Such conditions might apply to vault entry, for example; the special conditions would allon correlation of a particular entry witn the authorization for that activity.

- Enforce security regulations qovernina those authcrized to enter, including prohibition of weapons or other contraband.

- Deiect and intercept clandestine entry, and repel Forcible entry. When necessary, mobilize and deploy on-site and off-site response forces.

The Personnel control element comprises a number of subsystems whose functions are integrated to accomplish the above control actions.

Barriers and intrusion detectors--Barriers isolate materials from unnecessary access, and channel authorized access through portal checkpoints. They must be monitored to prevent covert entry and to protect them against direct assault. Intrusion detectors arc used as widely as possible in order to provide continuous, complete coverage and to reduce security-force manning requirements. Barriers are intended to escalate the threshold of forcible entry, to complicate the problems of forcible entry above that threshold, and to provide delays sufficient to secure the facility and mobilize response forces.

Personnel identification--The determination that an individual attempting to enter an access zone is authorized to enter is made on the basis of personal identification. This identification requires the correlation of measured physical characteristics with stored data relating urique physical characteristics 
with a name and the name with authorization to snter. Two sets of data must be mairtained: pinsical data associated with name, and name associated with authorization, including any restrictinr conditions. The data file rust be protected against unauthorized changes or additions. The decision function, i.e. granting of admittance by correlation of measured or observed physical. characteristics with file data, must also be protected against collusion, dur ss, and override.

Credentials will be used in special situations where their inherent vulnerabilities can be countered by other system elements. In this context, a crodential is a device which delegates entry control to the individual who is to be admitted. Credentials introduce additional vulnerabilities that must be considered, such as falsification, transfer, or loss.

The protection afforded by the personnel identification is enhanced if entries are logged and reported to appropriate authority for independent verification. To ensure that the verification is truly independent, the data must be protected from tampering and must be transmitted to the appropriate authority. Logging of exits as well as entries permits listina persons currently within an access zone; such information is useful for security-force response action and for safety emergencies. Secure logging of data for use by independent authority at a separate location requires sone form of contralized entry control.

Surveillance and Assessment- Various personnel control functions are accomplished with the aid of emplaced devices for remote observation, mainly closed-circuit television (CCTV). This monitoring system, with controls ard integrated displays, functions as an extension of direct observation by the security force. It complements intrusion detection by providing rapid, confirmatory assessment of indicated intrusions. It allows immediate, direct observation of critical areas in emergencies, enhancing coordination and control of response actions.

Security forces--The security force includes the person$\therefore$ who operate the Personncl Control element, as well as patrol a. I response forces with appropriate equipment for routine and rrergency guard-force actions.

An objective is to relieve security-force personnel of boring, repetitious tasks by automating those functions wherever appropriate. Guard duties will shift from those of patrolmen more toward operators of sophisticated equipment while remaining ready for immediate depleyment as coordinated armed units.

The postulated thriat of overt attack by well-organized, armed groups poses a special problen. Private guard forces operate under a wide range of legal constraints, ranging from constititional restrictions to crininal and tort law to common law. 
Criminal and tort laws differ in various jurisdictions. Commcr law is based on precedents and accepted practices that are rocted in locar rustom: typicaliy the intibitions on the use of force are les: restrictive in the south and west than in the east. In general, private guards are permitted in principle to use deadly force under certain circumstances, but always with the obligation to use no more force than is reasonable and necessary, and to be liable for the consequences. The effect is to shift the burden of asponsibility to individual guards at times of severe stress. They may be expected to proceed very cautiously in the application of deadly foree, and they will be at a serious disadvantage if they face aggressive, determined adversaries.

There aie also limitations of law-enforcement-agency response that must be addressed realistically in the safeguards system design. The kind of police support required for typical industrial security organizations is widely available--police must come to arrest offenders who are detained temporarily by guard forces, or to investigate after a crime las been committed. If it is necessary for police to provide armed forces quickly enough and in sufficient strength to overcome a heavy armed attack before the theft is completed, most police forces would not be adequate. There are few locations where police could respond as organized combat units who could overcume the postulated threats in a pitched battle, within a short period of time after being called. Giver sufficient time, police can arrive at any location in numbers that could eventually prove decisive, provided that the materials had not passed beyond the point of recovery in the meantime. It is worth noting that current regulations require oniy that iicensees call police when in jeopardy, and that they provide reliable communications to do so.

The safeguards system design must reflect these limitatons. The effect on the design against forcible theft is heavy reliance on passive barriers, the restriction of material accessibility, and protected defensive nosicions for guards. It is not necessary for the safeguards system to capture or kill adversaries; it is only necessary that control of the material be maintained. The system should be designed to withstand a protracted siege, and the sequence of actions necessary for an adversary to gain ultimate control of the materials should be attacked at many points. Delay should be exploited, and the uncertainty of success as perceived by the adversary should be enhanced wherever possible. Increased delay of the adversaries will correspondingly increase their probability of failure. Given sufficient delay, police support will be ultimately decisive; first, by sealing off the general area to maintain contact as adversaries attempt to break out, and eventually to overcome them. The mission of the safeguards systems must be to provide decisive delay rather than to overcome adversaries in a direct, armed confrontation. 


\section{Item Operations Control Filement}

The Personnel control element will restrict access to materials to those who have assignments to specific work locations. Beyond that, it is necessary to protect agairst unauthorized activities by those employees who may be acting in collusion or under duress. Additional in-depth defense can also be provided against forcible theft if control means can be applied directly at the points of material access. The Item Operations control element provides direct protection of materials at certain parts of the material flow strean, where the material is handled as discrete items.

In particular, operations such as unloading incoming shipments of feed material, handling of containers for weighing and assay, moving containers from the unloading dock to the storage vault and from storage to the container unloading station, and the handling operations involved in the storage, packaging, and loadout of product items are appropriate for item operations control. Such activities are not closely coupled to process operations, and transients introduced into the material stream at those points should be manageable. Where bulk matrials are in process, particularly in automated operations, the Materials Measurenent and Accounting element, acting through the production process control coordinator, is the means for detecting and intarcepting unauthorized material flows.

All systems for direct, physical control, whose function is preventive rather than deterrent, detective, or consequence limiting, operate as closed loops. That is, the operational activity is measured against a standard of acceptability and any necessary corrective action is imposed before the activity has progressed to the point that control is no longer possible. (As we use it here, the term closed loop is not intended to imply that a human operator is necessarily precluded as an element in the loop). The standard is a description of an operation as a sequence of monitor signals corresponding to the steps necessary to perform the operation, an authorization permitting the operation, and other information such as the identification of operators and material items. As the operation proceeds, monitor signals are generated and transmitted to a remote control point. Such signals might be generated by door opening or closing, personnel identification, handling-equipment status, and remote readout of labels and seals. The acceptance criteria for the monitor signals is made as broad as possible consistent with the purpose, so as to draw a proper balance between flexibility of the operation and the desired safeguards control. A discrepancy between the signals and the acceptance criteria is indicative of a particular state of affairs, for which there is an appropriate response. closed-10op control implies direct control action to force the operation back to an acceptable state: it could 
interrupt the operation by shutdown of handling equipment, fail to enable a subscquent step in the operation, or deny personnel entry. Specific riard responses could also be programmed, ranging from alert signals to more restrictive exit contzols to full emergency deployment.

The Item control elenent must be designed to prevent bypass of monitor and control signals and tampering with authorizition and acceptance information. Signals should not be originated by operating personnel, and circuits and devices should be designea against tampering.

The Item Control element is an important defense against overt attack, forming in effect a part of the barrier system. Barriers must allow passage of personnel and materials at certain points for normal operations; those points must be secured to closed the barriers when a threat is imminent. Places where materials are concentrated and relatively portable are likely targets for forcible theft, where an adversary would seize temporary control in order to move the materials out. The capability of the Item Control element for remote, overriding control could inmobilize the materials and thereby gain substantial additional delay time. The control could be imposed even though the penetration were undetected to the point of actual contact with the materials. In order to provide that protection against forcible theft, the material packaging and handling equiprnent would be designed to maximize the difficulty of handing by improvised means or bypass of the regular equipment.

\section{Materials Measurement and Accounting Element}

The Materials Measurement and Accounting system element (MMA) combines conventional chemical analysis, piece counting, and weighing with the real-time measurement and surveillance capabilities provided by nondestructive analysis (NDA) instrumentation. MMA is configured to provide rapid and accurate assessment of the location and amount of material in a plant, as described in reports on the Dynamic Materials Control system (DYMAC) (ref. 1, 2). The major characteristics of the system are:

1. A network of in-line and at-line measurement instruments relying heavily on NDA instruments to provide timely quantitative analysis and verification.

2. Direct, automated transfer of data from the plant floor and the chemical laboratory to a central accounting compurer system.

3. An automated accounting system to assess frequent material balances for small segments of the plant. 
4. Maintenance and managoment of a comnon

nuclear material data base for safe-

guards, quality assurance, process

control, and safety.

In MMAS, the facility is partitioned into discrete accounting envelopes designated as Item Control Areas (ICA), Unir: Processes (UP), or Matierial Balarice Areas (MBA). An ICA is an accounting envelope in which all materials are in identifiable containers and is almost always a storage vault or process line buffer storage. A UP is an accounting envelope for in-process materials consisting of one or more chemical or physical processes defined on the basis of process logic, material residence time, and accessibility for measurement. In this concept an MBA may be broadly defined, by means of software, as any combination of ICAs and UPs for which material balancing is desired. Conventionally, MBAs have been defined on the basis of geography and function, and most safeguards regulations on accounting and naterials control a'e stated in torms of MBAs and their custodianship.

All material flowing into and out of a unit process, including residues, waste, and holdup, are measured using NDA equipment or the most rapid chemical analysis methods available. Measurement data are used to record transactions of material flows, from one unit process to another, in a central accounting computer. The same procedure is employed for ICAs, except that a simple verification may be performed instead of a quantitative measurement. The time required to close a material balance around a unit process is limited primarily by the material residence time.

Control charts based on appropriate statistical algorithms can be used to detect significant anomalies in the material inventory within the unit process resicience time. Long-term drifts can be charted and appropriate alarm levels set. In effect, then, the detailed assessment provided by real-time unit process accounting forces a potential diverter to steal sisM in sufficiently small quantities that his individual removals will be masked by measurement uncertainties; thus, to obtain a sizeable quantity of material, the diverter must commit many thefts with the concomitant high risk of detection by the accounting system as well as by surveillance instruments, doorway monitors, and physical protection systems.

\section{Effectiveness Evaluation: Physical Protection}

The question of how effective the physical protection parts of the safeguards system would be against various postulated threats is very complex. It involves the details of physical plant layout, the performance of alarm and assessment devices, the delays afforded by static barriers when attacked by adversaries of varying capabilities, and above all, the performance of guard forces under conditions of extreme stress. 
Considerable progress has heen made in the development of dynamic simulation models that provide comparative evaluations and tradeoifs among system parameters. That work is described in another paper in these proceedings. There are two models, one centered on overt, external attack and one on the insider threat. Both compute times to penetrate sequences of barriers and response times initiated by detection at various poirts in the sequence. The outsider model determines the outcome on the basis $c:$ an armed clash between adversaries and response forces. The insi :er mcdel considers a theft attempt to be successfully thwarted if the adversary is directly confronted by a guard before he has left the premises. Both models can treat input variables in the form of probability distributiors, and the outcomes are probabilistic on the basis of series of tonte Carlo runs. The insider model js capable of accommodating ranges of skills, knowledge, and access: by insiders which are used to defeat individual parts of the safeguards system.

The modeling of event sequences as complex as those involving plant-wide safeguards systems is very complex, and much remains to be done. In particular, the decision criteria need to be broadened to cover a wider range of physical protection strategies. The outsider model measures success in terms of a direct, armed confrontation, and success against the postulated high-level threat is usually conditional upon ievels of police response tinat are typically unavailable. As indicatec earlier, successful defense against the high-level attacks that are postulated probably requires a strategy of avoidance of a direct showdown for an indefinite period while preventing movement of materials offsite. With the passage of time there will be a steady increase in the numbers of police arrivals, and a corresponding increase in the probability of a favorable outcome. The armed confrontation by the on-site guards at the earliest possible time, reinforced by organized police combat units when they arrive, is the only situation depicted by the model in its present stage of development. It does not cover various complexities such as hostages, feints, and multiple attacks.

The models have provided very useful results in their present forms. They have provided valuable insights into the effects of incremental changes in detection and delay capabilities of barriers and alarms. They will continue to be developed in parallel with system designs, and they are valuable aids to the understanding of complex system interactions.

\section{Effectiveness Evaluation: Materials Accounting}

The mathematical simulation of a safeguards materials accounting system for a model nuclear facility provides:

(a) The ability to predict the response and sensitivity to diversion of the system under a given set of normal or abnormal conditions. 
(b) A test of computer algorithms for diversion ind.cators.

(c) A means for comparing and evaluating alternative safequards systems instrumentation, procedures, and operation.

Sensitivity of a safeguards materials accounting system to both short-term and long-term diversion of nuclear material is of immediate interest. The sensitivity depends in a complex manner on measurement uncertainties, the interrelationships between various segments of the facility process, and the flow of material through the process. Accordingly, mathematical simulation is perhaps the only effective means of evaluating the degree of material control attainable.

Figure 2 is a simplified flow diagram of a generic unit process, as defined in the DYMAC concept. Each material flow line can represent several parallel streams. Measurements of each stream are required to close a true material balance. Sensitivity of the safeguards materials accounting system to diversion is evaluated by means of simulations of material flows and measurements for each unit process.

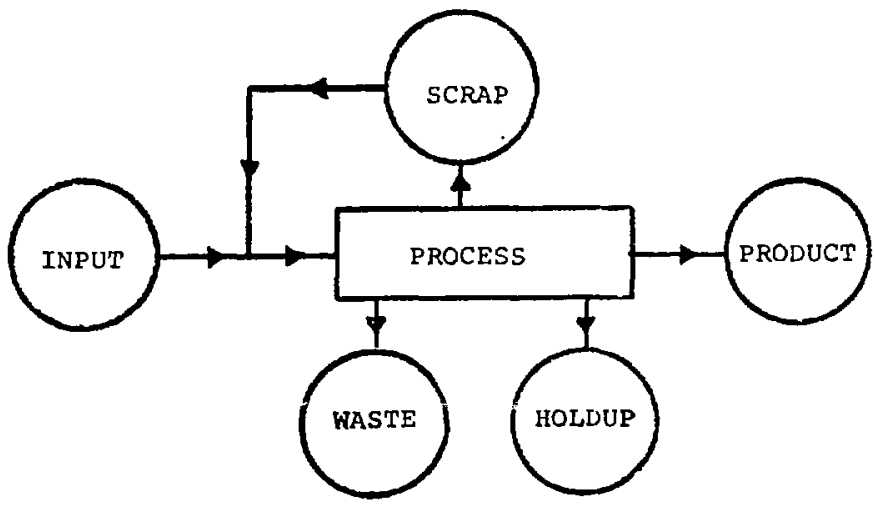

Figure 2 - Generic unit processes.

Diversion indicators are based on statistical analyses of the materials measurements. Diversion falls in two catesories. Short-term diversion refers to the single theft of a relatively 
large amount of nuclear material. Conventional probability arguments provide diversion indicators for single theft events. Sensitivity of the single theft indicator is determined by the acceptable false alarm rate. The detection probability for a specified false alarm rate depends nnly on the material balance measurement uncertainties and the size of the theft.

Long-term diversion refers to the repeated thefts of amounts of nuclear material sufficiently small that each will be undetected because of measuremen uncertainties. A long-term diversion indicator must detect a given level of diversion after the smallest number of material balances have been dram consistent with an acceptable false alarm rate. The cumulative sum (cusum) of unit process material balances provides a striking indicator of this type of diversion. Cusum plots give strong visual evidence of diversion while computer analysis of the cusum data provides quantitative estimates of the diversion level.

The diversion information contained in material balances from a sequence of unit processes has some redundancy. This redundancy can be exploited to provide timely detection in twc ways: (a) the short and long term diversion indicators can be apolied to material balance data fron any subset of unit processes; (b) powerful filtering techniques can also be applied to materia? balance data from a series of unit processes. Both methods reduce the uncertainty in the material balance estimates, thereby increasing the diversion detection probability.

Mathematical simulation of the operation of the materials measurement and accounting element is an effective technique. since all the parameters are directly quantifiable, and system performance is measured in mathematical terms. The development of models to simulate system performance is thus a straightforvard, if complex, task, and a considerable amount of work has already been done.

\section{summary}

Nuclear facilities mugt be safeguarded against a wide range of postulated threats, both internal and external. Incremental extensions of conventional safeguards measures will offer marginal improvements in protection ac tine cost of potentially severe impacts on plant operations. The safeguards system must be closely integrated to coordinate its component elements and to insure that effectiveness is attained without unnecessary disruption of plant operations or compromise of safety requirements. An integrated system comprising personnel control, item handing control, and materials measurement and accounting, appropriately coupled with plant operational control, forms a safeguards system structure that promises to provide enhanced effectiveness against a broad range of threats without unnecessary impact on operations. 


\section{References}

1. Keepin, G. R., anc. W. J. Maraman, "Non-Destructive Assay Technolugy and in-Plant Dynanics Materials Control-DYMAC," IAEA International Symposium on the Safeguarding of Nuclear Materials, Vienna, October 20-24, 1975.

2. Augustson, R. H., "Dove? apment -f Ir.plant Real-Time Materials Control--The DYMAC Program," 1976 INMM Proceedings, June 22-24, 1976.

\section{Acknowledgments}

The authors are grateful to a host of colleagues at the Los Alamos Scientific Laboratory and Sandia Laboratories for their contributions and to representatives of various indistry and government organizations for their useful comments. In particular, the key contributions of Dr. J. B. Shipley in the design of the integrated safeguards configuration and its relationship to tho plant Eunctions is acknowledged. Dr. D. D. Cobb supplied the description of simulation of unit-processing accounting. 